Revista Complutense de Historia de América

ISSN: $1132-8312$

https://dx.doi.org/10.5209/rcha.64688

\title{
Entre pinceles y cuadros. Los libros del pintor Miguel Cabrera
}

\author{
Cristina Ratto ${ }^{1}$
}

Recibido: 8 de noviembre de 2018 / Aceptado: 22 de abril de 2019

Resumen. En mayo de 1768, tras la muerte de Miguel Cabrera se inició el trámite para el inventario y aprecio de sus bienes. Con este fin, se designó a personas conocedoras, vinculadas con la práctica de los oficios, quienes realizaron la valuación. El documento ofrece un amplio panorama que evoca en el ámbito novohispano el tópico el "tópico de la casa del pintor". Sintomático de ello es que, de la amplia gama de bienes registrados, los libros y los cuadros recibieran una atención especial. A partir del estudio del inventario de su biblioteca -en relación con el resto del documento- es posible discutir algunos aspectos de su modo de pintar, así como proponer en qué medida los libros del pintor pueden contribuir a la interpretación de diversos aspectos de su obra. Más que dilucidar si Miguel Cabrera fue cabalmente un "pictor doctus", se pone de relieve en qué medida un análisis diferente del conjunto de sus libros contribuye a matizar y redefinir esta etiqueta en el panorama de la pintura novohispana del siglo XVIII. Sobre todo, se plantea que no es la cantidad de libros, ni su simple clasificación temática, lo que convierte a un pintor en un "artista liberal". En consecuencia, el tema abre paso a nuevas reflexiones.

Palabras clave: Cultura visual; cultura letrada; cultura novohispana; Miguel Cabrera; Historia del Libro; Historia del Arte; siglo XVIII.

\section{[en] Between Paintbrushes and Paintings. The books of painter Miguel Cabrera}

Abstract. After the death of Miguel Cabrera in May of 1768, the inventory and assessment of his
properties was initiated. Knowledgeable persons with links to the painting trade were appointed to
carry out the assessment. The document offers a broad perspective that, within the framework of New
Spain, evokes the topic "the painter's home"; The fact that the books and paintings were the object of
special attention among the wide range of goods registered, reflects this idea. The study of the inventory
of Cabrera's library, with respect to the rest of the document, allows us to discuss some characteristics
of his painting techniques and assess how the painter's books could contribute to an interpretation
of different aspects of his work. More than elucidating if Cabrera was truly a "pictor doctus", the
study underscores to what degree a different analysis of his book collection may help to qualify and
redefine this term within the framework of the art of painting in New Spain in the 18th century. More
importantly, it proposes that the quantity of books and their simple thematic classification are not what
define a painter as a "liberal artist". As a result, it paves the way to new questions. Keywords: Art History; History of books; Visual culture; Literary culture; Culture of New Spain; 18th Century.

Sumario. 1. Introducción. 2. Sobre los pintores y sus libros. 3. Los libros de Miguel Cabrera. 4. Conclusiones. 5. Referencias bibliográficas.

1 Facultad de Filosofía y Letras, Universidad Nacional Autónoma de México [México].

E-mail: cristinaratto64@gmail.com 
Cómo citar: Ratto, C. (2019) Entre pinceles y cuadros. Los libros del pintor Miguel Cabrera, en Revista Complutense de Historia de América 45, 89-112.

\section{Introducción}

En mayo de 1768, tras la muerte de Miguel Cabrera, su esposa, Ana María Solano, en calidad de albacea, inició el trámite para el inventario y aprecio de los bienes, de acuerdo con lo dispuesto en el testamento del pintor ${ }^{2}$. El menaje del hogar -tanto los enseres domésticos, como los efectos personales- fue clasificado y meticulosamente tasado. Con este fin, se designó a "peritos inteligentes" -es decir, personas conocedoras, vinculadas con la práctica de los oficios, especializadas en cada una de las materias-. Muebles, joyas, platería, ropa, arreos y aparejos dan testimonio de la vida de un artista con fama y prestigio, tanto como recuerdan el "tópico de la casa del pintor", del que son ejemplos célebres Rubens, Rembrandt, incluso Velázquez. Sintomático de ello es que, de la amplia gama de bienes registrados, los libros y los cuadros recibieran una atención especial. Juan Patricio Morlete Ruiz - colega de Cabrera-estuvo a cargo del "avalúo de pintura y libros anexos a ella", así como el librero José Navarro se encargó del resto de los impresos. De estas circunstancias surgen dos cuestiones: el artista novohispano había reunido un conjunto de libros cuyo valor se consideró necesario aquilatar, en la medida que se incluyeron como parte de sus posesiones; asimismo, algunos de ellos fueron clasificados como objetos directamente vinculados a su práctica profesional. Si se tienen en cuenta ambas observaciones, a partir del examen del inventario de su biblioteca -pero sin desvincularlo del resto del documento- es posible vislumbrar algunos aspectos de la práctica de la pintura a mediados del siglo XVIII en Nueva España.

Miguel Cabrera habría nacido en Oaxaca a finales del siglo XVII; sin embargo, su primera actividad documentada en la capital del virreinato data de 1740 . Como cabeza de un gran taller, alcanzó un sólido prestigio y se convirtió en uno de los artistas más prolíficos. Trabajó para los clientes más importantes: fue pintor de cámara del arzobispo Rubio y Salina (1749-1765), satisfizo múltiples encargos para la Compañía de Jesús, no sólo en la ciudad de México, y trabajó para diferentes clientes en los grandes centros mineros -Taxco, Querétaro y Guanajuato. Cultivó diversos géneros y formatos, desde grandes ciclos narrativos y alegóricos, hasta retratos y pintura de castas. Dominó el óleo sobre cobre y lienzo. También fue versátil en cuanto al manejo de recursos expresivos: podía apelar a intensos claroscuros, tanto como incorporar tonalidades suaves y diáfanas ${ }^{3}$. Sin duda, la posesión de un conjunto de libros hace aún más rica y compleja su figura: en la medida que la biblioteca contribuiría a esclarecer ciertos aspectos de su práctica artística, su obra haría visibles algunos de los intereses como lector.

2 Memoria, descripción e inventario de los bienes que quedaron por fin y muerte de don Miguel de Cabrera. Ciudad de México, 26-V-1768 a 19-VIII-1768. Archivo Enrique A. Cervantes [México], sin signatura, ff. 1-35. El documento, de 35 fojas, fue publicado por Guillermo Tovar de Teresa y de acuerdo con lo indicado pertenecía al Archivo Enrique A. Cervantes (Ciudad de México). Tovar de Teresa, 1995: 269-293.

3 Sobre Miguel Cabrera: Toussaint, 1965; Carrillo y Gariel, 1966; Burke, 1992; Tovar de Teresa, 1995; Rishel Stratton-Puitt, 2007; Alcalá - Brown, 2014. 


\section{Sobre los pintores y sus libros}

Aunque desde principios del siglo XX la erudición y los estudios de carácter empírico comenzaron a revelar que algunos artistas durante el Antiguo Régimen poseyeron libros, fue hasta la década de 1980 que los inventarios de bibliotecas o la identificación de algún ejemplar anotado dejó de ser algo más que un dato. Desde entonces los historiadores del arte han empezado a relacionarse con los historiadores del libro. En particular, el interés en los inventarios ya conocidos, tanto como el descubrimiento de nuevos, se vinculó con un tema que en la medida que crecía mostró nuevas facetas: la relación entre artes liberales y pintura y el surgimiento del concepto del pintor como artista liberal ${ }^{4}$.

Desde el siglo XV Leon Battista Alberti había recomendado que el pintor debía estar familiarizado con las artes liberales y los studia humanitatis. Sin embargo, fue la circulación impresa de su tratado durante el siglo XVI, además de las obras de Giorgio Vasari, Ludovico Dolce y Giovanni Paolo Lomazzo -entre otros-, las que difundieron y enriquecieron la idea con distintos matices. Posteriormente, en el ámbito hispánico, entre mediados del siglo XVII y principios del XVIII, tanto Francisco Pacheco como Antonio Palomino profundizaron en la imagen ideal de un "pintor erudito". No obstante, si sólo se tiene en cuenta la reconstrucción de sus bibliotecas -a través de inventarios o mediante la identificación de algunos ejemplares anotadosapenas unos cuantos artistas durante el Antiguo Régimen podrían ser considerados cabalmente como pictor doctus. Pese a que cada vez mayor número de ellos pretendió alcanzar ese ideal, la pintura continuó siendo una técnica y la formación del pintor estuvo centrada en el taller ${ }^{5}$. Así, más allá de los conceptos derivados del ut pictura poesis discutidos ampliamente en la teoría del arte, los tratados siempre dedicaron, en mayor o menor medida, una parte de sus reflexiones a cuestiones técnicas relacionadas con diferentes aspectos de las prácticas de taller y sólo algunos de ellos cuentan con recomendaciones precisas sobre la formación intelectual del artista. Ambas facetas fueron conjugadas con distinto énfasis en circunstancias específicas, pero a pesar de los matices la importancia dada a los conocimientos técnicos, tanto como a la preparación intelectual, puede rastrearse en las obras de Giovanni Battista Armenini, para finales del XVI, en las de Vicente Carducho y Francisco Pacheco, para mediados del siglo XVII, y en la de Antonio Palomino para las primeras décadas del XVIII.

En particular el tratado de Armenini, De veri precetti della pittura, publicado en Ravena en $1587^{6}$, conjugó detalladas explicaciones prácticas -orientadas hacia la

$4 \quad$ El estudio Jan Bialostocki, "The Doctus Artifex and the Library of the Artist in the XVIth and XVIIIth Centuries", constituye un punto de partida en este cambio de perspectiva que, más allá de la recuperación y transcripción de los inventarios de los libros que pertenecieron a algunos pintores famosos, avanza hacia el planteamiento de diferentes problemas sobre la práctica artística. Bialostocki, 1988: 150-165. Desde entonces el tema ha crecido y los estudios se han multiplicado. En particular, dentro del ámbito académico español, las posibilidades que ofrecen las bibliotecas de artistas, a partir de enfoques que excedan el análisis cuantitativo, han sido señaladas por Gállego, 1972; Marías - Bustamante García, 1981 y Portús Pérez, 1999. Asimismo, las más recientes discusiones sobre el tema se recogen en Damm - Thimann - Zittel, 2013. Los aportes reunidos en este libro subrayan la importancia de ampliar los ángulos de observación a través del cruce de diferentes campos de estudio. También proponen extender la exploración hacia diversos espacios culturales y contemplar las visiones tanto sincrónicas como diacrónicas, para de tal modo discutir sobre la formación, los hábitos de lectura y la relación de los artistas con numerosas áreas de conocimiento.

5 Kagan - Marías, 2014: 15-39.

6 Armenini, 1587. La primera edición crítica en español: Armenini, 1999. 
transmisión sistemática de los conocimientos de taller- con reflexiones que hacen evidente una valoración crítica de los principios de la pintura romano-toscana y lombardo-véneta ${ }^{7}$. Para Armenini -en una clara paráfrasis de Alberti-el pintor debía dominar la técnica con maestría, tanto como poder reflexionar acerca de los principios de la pintura, de tal modo que teoría y práctica mantuvieron una relación recíproca en sus reflexiones. Significativamente, Armenini hizo recomendaciones bibliográficas precisas que resultan útiles, como parámetro de referencia, para interpretar las bibliotecas de los artistas, así como sus consejos pueden funcionar como un punto de partida para el acercamiento a los modos de lectura. El mismo Armenini ordenó sus sugerencias de acuerdo con cuatro campos temáticos ${ }^{8}$. En primera instancia advirtió que, para el estudio, el pintor debía considerar "los libros de Historias Sagradas": la Biblia, el Nuevo Testamento, la vida de Cristo y de la Virgen, las leyendas de los santos, el Apocalipsis y los Santos Padres. En igual medida insistió en la importancia del conocimiento de "materias profanas", en particular de la historia de Grecia y Roma. Destacó a autores antiguos como Tito Livio, Apiano Alejandrino, Valerio Máximo, y modernos como Petrarca -Virorum Illustrium - y Boccaccio -De Claris Mulieribus y Genealogio Deorum. En cuanto a la literatura, hizo sólo tres recomendaciones puntuales: las Metamorfosis de Ovidio, el Asno de oro de Apuleyo y el Amadís de Gaula. Por último, fue igualmente preciso en cuanto a los libros "relacionados con la pintura", señaló que el artista debía tener presente a Vitruvio, por supuesto a Alberti y a Serlio, además del tratado sobre la perspectiva de Daniele Barbaro9 ${ }^{9}$. Si bien parece difícil medir la fortuna del tratado de Armenini, dos aspectos resultan claros: por una parte, las sugerencias bibliográficas se fundaron en su experiencia, proveniente de una tradición consolidada durante el siglo XVI; por otra, muchos de los títulos y sin duda, los campos temáticos abarcados formaron parte de las bibliotecas de los artistas más allá del siglo XVII, tal y como lo testimonian algunos inventarios ${ }^{10}$.

Casi cincuenta años después de Armenini, en el entorno de la corte española, el pintor Vicente Caducho, con el fin de reunir argumentos que demostraran la condición liberal de su arte, reflexionó sobre la teoría y la práctica. A través del diálogo entre un maestro y su discípulo, Carducho buscó presentar de manera didáctica los principios fundamentales de una disciplina cuyo hacer debía fundarse en los conocimientos teóricos. En el primer diálogo, centrado en explicar cuál era la "dificultad del arte", señaló que para llegar a ser un buen pintor se debía "dibujar, especular, y mas dibujar [...]"11. Inmediatamente, proporcionó lo que podría interpretarse como un programa de lecturas básicas. Mencionó las obras con las que debía estar familiarizado un artista y dividió sus sugerencias por materias: anatomía, simetría, fisionomía, perspectiva, arquitectura, además de historia sacra y profana. Por ejemplo, señaló que en cuestión de anatomía era necesario que un pintor tuviera en cuenta a Vesalio y a Juan Valverde; sobre todo, los grabados de Johann von Calcar y los de Gaspar Becerra que ilustran aquellas obras, "para saber por ellos el sitio, forma,

7 Schlosser, 1993: 333-334. Aunque Schlosser considera el tratado de Armenini como "menor" y esencialmente "empírico", llama la atención sobre su riqueza como fuente para acercarse a las prácticas de taller, el comercio del arte, la formación del artista y la biblioteca del pintor.

Biaostocki, 1988: 150-165. Damm - Thimann - Zittel, 2013: 11. Kagan - Marías, 2014: 25-26.

Armenini, 1999: 264-265.

Kagan - Marías, 2014: 25-26.

1 Carducho, 1633: 2; 1979: 25. Sobre la literatura artística y la teoría del arte españolas son referencia obligada Calvo Serraller, 1999: 15-58 y más recientemente Riello, 2012: 6-20. 
tamaño, y efecto de los huesos, y musculos, que son las partes que deve saber el Pintor; dexando la calidad dellos, su virtud, oficio, y de sus acciones à los Medicos, y Cirujanos"12. Los contemporáneos de Carducho pudieron asumir sus recomendaciones como una guía. Desde el presente, son pistas que ayudan a entender los inventarios de las bibliotecas, tanto como un punto de partida para rastrear formas de lectura. De este modo, a partir de sus sugerencias, es posible interpretar -no sólo señalar-por qué algunos pintores poseyeron libros de anatomía muy especializados; también cuestionar en qué medida esos libros fueron "mirados", no "leídos".

Aunque Francisco Pacheco no sugirió autores de manera específica -tal y como lo hicieron Armenini y Carducho-, su tratado revela, a través de la profusión de citas en las que se funda, el conocimiento directo e indirecto de los autores de la tradición clásica y de las obras más importantes del siglo XVI y de la primera mitad del $\mathrm{XVII}{ }^{13}$. En este sentido, las meticulosas alusiones a libros y autores pudieron funcionar como un marco de referencia para un artista ávido de conocimientos teóricos y prácticos. De manera análoga, Antonio Palomino, a través de innumerables pasajes, insistió en que el pintor erudito debía fundar la práctica en el conocimiento de diferentes materias y en el estudio de diversos autores. En particular, con el pretexto de refutar la afirmación de Juan Caramuel, quien sostenía que sobre la pintura se había "impreso poco" y que aún eran menos las obras que merecían ser leídas, Palomino elaboró una verdadera bibliografía, la que en algunos casos incluyó formato, lugar y año de impresión de los libros ${ }^{14}$. Así resumió las principales publicaciones sobre arte entre finales del siglo XVI y principios del XVIII. Este detallado catálogo pudo interpretarse como un argumento en favor de la liberalidad de la pintura, en tanto que demostraba que los hombres de letras y los pintores, antiguos y modernos, habían reflexionado sobre la disciplina. También pudo funcionar como una guía de lectura para los artistas, dado que dividió los libros de acuerdo con los idiomas: castellano, latín, toscano, francés, flamenco, inglés y alemán; asimismo señaló brevemente las materias que trataban -por ejemplo, geometría, perspectiva, descripciones de obras y monumentos, tratados diversos y biografías - y en ciertos casos añadió comentarios concisos $^{15}$. Por otro lado, al describir la personalidad de Diego Velázquez, en una biografía concebida en términos de "memoria ejemplar", Palonimo subrayó, no sólo su dedicación al estudio, sino que ofreció una lista, quizá hipotética, de sus principales lecturas ${ }^{16}$.

12 Vesalio, 1543; Valverde de Amusco, 1556; Carducho, 1633: 2-2v; Carducho, 1979: 25-26.

13 Tanto Jonathan Brown como Bonaventura Basegoda i Hugas han revelado múltiples aspectos de la erudición de Pacheco a través del análisis crítico de su tratado. Brown, 1980: 56-77; Pacheco, 2001: 11-70.

14 Palomino cita a Caramuel Lobkowitz. De acuerdo con Caramuel "De el arte de pintar no se han impresso muchos libros; y dignos de ser leidos, hay muy pocos". Caramuel Lobkowitz, 1678, t. II: 42. Sorprendido por tal afirmación, Palomino aprovecha la oportunidad para demostrar su erudición frente al filósofo, matemático y teórico de la arquitectura: "Estoy cerca de persuadirme, ò que no avia llegado à su noticia lo mas peregrino, que se hà escrito de esta Facultad; ò que à mi me pareçe tal, por no medirse mi cortedad con lo elevado de su talento; pero como quiera que sea, porque otro no incurra en semejante arrojo, harè aqui un breve Resumen de lo que yo tengo visto, y sè que se hà escrito de esta Facultad en varios Idiomas [...]”. Palomino, 1715, t. I: 163-164.

15 Palomino, 1715, t. I: 163-170; Schlosser, 1993: 25.

16 "Exercitabase en la leccion de varios Autores, que han escrito de la Pintura elegantes preceptos: inquiria en Alberto Durero la Symetria del cuerpo humano; en Andrès Bexalio la Anathomia; en Juan Bautista Porta la Fisionomia; la Perspectiva en Daniel Barbaro; la Geometria en Euclides; la Arithmetica en Moya; la Arquitectura en Vitrubio, y el Viñola; y otros Autores; en quien, con solicitud de abeja, escogia ingeniosamente para su uso, y para provecho de la posteridad, lo mas conveniente, y perfecto. La Nobleza de la Pintura examinaba en Romano Alberti, escrita à instancia de la Academia Romana, y Venerable Hermandad del Glorioso Evangelista 
Resulta muy difícil juzgar cuántos artistas tuvieron un ejemplar de la obra de Armenini, de los Diálogos de Carducho, del tratado de Pacheco o, un siglo más tarde, de los tres volúmenes de Palomino, o cuántos los leyeron y hasta qué punto atendieron sus preceptos. Sólo como indicio, todo parece indicar que el libro de Armenini estuvo en las manos de Diego Velázquez ${ }^{17}$; también fue leído y citado por Francisco Pacheco $^{18}$. Así como los libros de Armenini, Carducho y Pacheco formaron parte de la dilatada biblioteca de Melchor Pérez de Soto, el maestro mayor de la catedral de México que, a mediados del siglo XVII, procesó la inquisición por "practicar astrología judiciaria y por poseer libros sobre aquella oscura materia"19.

Ahora bien, una cosa son las bibliotecas y otra el conocimiento, una cosa es tener libros y otra es leerlos ${ }^{20}$. En este sentido el panorama es muy rico y lleno de matices. Los casos de grandes y pequeñas bibliotecas son sorprendentes en muchos sentidos. Por ejemplo, Poussin, considerado por Bellori como el ideal de pictor doctus sólo tuvo 19 libros. Rembrandt, quien recibió una educación general poseyó 22; sin embargo su obra revela el conocimiento y la comprensión de la literatura clásica y de la historia sagrada ${ }^{21}$. El Greco había reunido a lo largo de su vida $130^{22}$. El inventario a la muerte de Velázquez demuestra que el gran pintor de Felipe IV tenía 154 volúmenes ${ }^{23}$. Sin embargo, puede estimarse que la biblioteca de Rubens -el pintor cortesano, el diplomático y el gran coleccionista- contuvo alrededor de 500 títulos ${ }^{24}$. Una última comparación hace evidente que el análisis cuantitativo es sólo una variable que es necesario considerar a la luz de otros factores. De acuerdo con el registro levantado a su muerte en 1597, Juan de Herrera -el arquitecto de Felipe II- había reunido una biblioteca de 750 libros, entretanto su colega novohispano, Melchor Pérez de Soto, poseía en 1655 aproximadamente $1500^{25}$.

San Lucas: con la Idea, que escriviò Federico Zucaro de los Pintores, ilustraba la suya, y la adornaba con los preceptos de Juan Bautista Armenini. Y à executarlos con presteza; y brevedad, aprehendia en Michael Angelo Viondo. El Vasari le animaba con las Vidas de los Pintores Ilustres y el Riposo de Rafael Borghini, le constituia erudito Pintor. Adornose también con la noticia de Sagradas, y Humanas Letras, y otras cosas importantes, para fecundar la mente con todo linage de erudicion, y noticia universal de las Artes. Assi lo aconseja Leon Bautista Alberti por estas palabras: Mà ben vorrei, chel Pittore fosse dotto, quanto possibil fosse, in tute l'Arte Liberali; mà sopra tuto gli desidero, che sia perito ne la Geometria. Era tambien familiar, y amigo de los Poetas, y de los Oradores: porque de semejantes Ingenios recibia ornamento grande para sus composiciones". Palomino, 1724, t. III: 324.

17 Kagan - Marías, 2014: 25.

18 Pacheco, 2001: 265-276.

19 Ynventario de los libros que se le allaron a Melchor Perez de Soto vecino desta ciudad y obrero mayor de la santa yglesia cathedral de ella. Los quales se metieron en la camara de el secreto deste santo officio. Ciudad de México, 13-I-1655 a 13-X-1655. Archivo General de la Nación [México], Inquisición, vol. 440, exp. 1, ff. 1-103v. En este inventario el registro "verdadero presepto de la pintura por Batista Armeni" (f. 45v) puede identificarse como Armenini, 1587. La anotación "Otro yntitulado dialogos de la pintura su defensa y origen" (f. 10f) seguramente corresponde a Carducho, 1633. La inscripción "Arte de la pintura su antiguedad y grandesas por Francisco Pacheco" (f. 37v) sin duda se refiere a Pacheco, 1649.

20 Kagan - Marías, 2014: 23.

21 Sobre las estimaciones de la cantidad de libros que poseyeron algunos artistas con referencias puntuales a estudios y fuentes primarias: Damm - Thimann - Zittel, 2013: 6-9, 25-26; Kagan - Marías, 2014: 23-24.

22 Sobre la biblioteca de El Greco puede consultarse el más reciente estudio con amplias referencias bibliográficas y análisis de fuentes primarias, Docampo - Riello, 2014.

23 Sobre la biblioteca de Diego Velázquez: Sánchez Cantón, 1925, 1942 y 1960; Ruiz Pérez, 1999; Portús Pérez, 2008 .

24 Sobre los libros de Rubens: McGrath, 1997: 55-67.

25 Ruiz de Arcaute, 1936: 150-171; Ratto, 2016. 
En consecuencia, los inventarios de libros deben ser leídos desde distintos ángulos con el fin de avanzar con mayor cautela en la formulación de inferencias en torno a dos cuestiones clave sobre la relación entre pintura y cultura letrada durante el Antiguo Régimen. ¿Qué aspectos del equipamiento mental de un artista es posible conocer a través de una lista escueta de libros? Lista que es necesario interpretar para tratar de vislumbrar una imagen muchas veces borrosa de una biblioteca. ¿Cómo se vincula ese conjunto de libros con el perfil de su propietario y con su actividad profesional? En igual medida, resulta crucial tener en cuenta que una biblioteca no es un conjunto coherentemente previsto por su dueño y que el inventario ofrece la imagen muchas veces fragmentaria de una colección de libros que, por distintas circunstancias, ha cambiado a lo largo del tiempo. Ni el inventario, ni la biblioteca hacen evidente todos los intereses de su propietario, ni narran los largos procesos de formación de una biblioteca. Asimismo, los inventarios sólo ofrecen un ángulo de observación sobre situaciones complejas y variadas. Es decir, no necesariamente un artista con pocos libros es un simple artesano o un artista con muchos es un pictor doctus ${ }^{26}$.

\section{Los libros de Miguel Cabrera}

El análisis preliminar del inventario levantado a la muerte de Miguel Cabrera revela que el artista novohispano tenía un total de 75 títulos, los que representaban 84 volúmenes. Aunque la información no es completa -como suele suceder en los inventarios post mortem-, formatos y precios se anotaron de manera escrupulosa, en tanto que los títulos y los autores fueron registrados con cierta exactitud, de tal modo que es posible identificar una parte considerable de las ediciones. De acuerdo con el aprecio realizado por Patricio Morlete Ruiz y por José Navarro, sus libros valían 434.50 pesos -es decir, representaban el 5\% de los 8372 pesos en que fueron tasados sus bienes muebles. Del total de los volúmenes, 23 eran en folio y sus precios oscilaron entre 1.50 y 51.50 pesos; 20 eran en $4^{\circ}$ y valían entre 1 real y 5 pesos; finalmente 41 eran de $8^{\circ}$ y $16^{\circ}$ con un valor entre 1 real y 1 peso. De tal modo que, en términos cuantitativos, la biblioteca resulta significativa, aunque no excepcional. Aún más, si se compara el volumen de los objetos y los montos producto de la valuación, es posible observar que el $46 \%$ del capital de bienes muebles reunidos por el pintor estuvo constituido por joyas, alhajas y plata labrada-las que representaban el $11 \%$ de los registros-, el $19 \%$ por las pinturas que se encontraron en su taller-las que constituían el 30\% de sus bienes-y el 5\% de libros -los que equivalían al 17\% de los objetos. En consecuencia, podría decirse que los libros formaron una parte notable de sus bienes, en cuanto a cantidad y precio, pero sin duda no la más significativa. Asimismo, en un primer análisis, en cantidad y valor, no fueron sus pertenencias más costosas. Sin embargo, es necesario considerar el inventario desde otros ángulos. Por ejemplo, no parece sorprendente que los libros en folio, especialmente las dos Biblias, fueran los volúmenes más valiosos, los que son comparables en precio con algunas de sus pinturas y algunas de las joyas ${ }^{27}$ (Tablas 1 y 2 ).

26 A partir del señalamiento y la discusión de estos problemas básicos, José Riello replantea el análisis del inventario de la biblioteca de El Greco. Riello, 2014.

27 La joya más costosa registrada fue "un par de pulseras de perlas, en treinta y ocho hilos y pesos de nueve onzas y una ochava, con chapetas de oro y en ellas veintiséis diamantes" valuado en 800 pesos. Sin embargo, 
Tabla 1. Análisis cuantitativo de los bienes inventariados a la muerte de Miguel Cabrera ${ }^{28}$.

\begin{tabular}{|c|c|c|c|c|c|c|c|c|}
\hline & Valuador & $\begin{array}{l}\text { Número } \\
\text { de inv }\end{array}$ & $\begin{array}{c}\text { Cantidad } \\
\text { de registros }\end{array}$ & $\begin{array}{l}\text { Porcentaje } \\
\text { de registros }\end{array}$ & & Valor & $\begin{array}{c}\text { Porcentaje } \\
\text { de los valores }\end{array}$ & \\
\hline Pintura & Juan Patricio & 1 a 131 & 131 & $30.90 \%$ & $30.90 \%$ & $\$ 1603.41$ & $19.15 \%$ & $19.15 \%$ \\
\hline Madera & $\begin{array}{l}\text { Gaspar de } \\
\text { Terrazas }\end{array}$ & 132 a 168 & 37 & $8.73 \%$ & & $\$ 191.43$ & $2.29 \%$ & \\
\hline $\begin{array}{l}\text { Objetos } \\
\text { dorados }\end{array}$ & $\begin{array}{l}\text { Agustín de la } \\
\text { Rosa }\end{array}$ & 169 a 188 & 20 & $4.72 \%$ & & $\$ 47.12$ & $0.56 \%$ & \\
\hline $\begin{array}{l}\text { Espejos y } \\
\text { vidrios }\end{array}$ & Santoyo & 189 a 192 & 4 & $0.94 \%$ & & $\$ 27.43$ & $0.33 \%$ & \\
\hline Cobre & Cayetano & 193 a 195 & 3 & $0.71 \%$ & & $\$ 42.00$ & $0.50 \%$ & \\
\hline $\begin{array}{l}\text { Forlón, mulas y } \\
\text { guarniciones }\end{array}$ & $\begin{array}{l}\text { Manuel } \\
\text { Álvarez }\end{array}$ & 196 a 199 & 4 & $0.94 \%$ & & $\$ 285.00$ & $3.40 \%$ & \\
\hline $\begin{array}{l}\text { Libros de } \\
\text { pintura }\end{array}$ & Juan Patricio & 200 a 212 & 13 & $3.07 \%$ & & $\$ 388.31$ & $4.64 \%$ & \\
\hline Alhajas & $\begin{array}{l}\text { Joaquín } \\
\text { Salvatierra }\end{array}$ & 213 a 247 & 35 & $8.25 \%$ & & $\$ 3311.75$ & $39.55 \%$ & \\
\hline Plata labrada & $\begin{array}{l}\text { Miguel } \\
\text { Basurto }\end{array}$ & 248 a 259 & 12 & $2.83 \%$ & $11.08 \%$ & $\$ 586.53$ & $7.01 \%$ & $46.56 \%$ \\
\hline $\begin{array}{l}\text { Ropa del } \\
\text { difunto }\end{array}$ & $\begin{array}{l}\text { Joseph } \\
\text { Mariano } \\
\text { Zamora }\end{array}$ & 260 a 280 & 21 & $4.95 \%$ & & $\$ 146.00$ & $1.74 \%$ & \\
\hline $\begin{array}{l}\text { Ropa de la } \\
\text { señora y las } \\
\text { niñas }\end{array}$ & $\begin{array}{l}\text { Joseph } \\
\text { Mariano } \\
\text { Zamora }\end{array}$ & 281 a 358 & 78 & $18.40 \%$ & & $\$ 1437.42$ & $17.17 \%$ & \\
\hline Libros & $\begin{array}{l}\text { Joseph } \\
\text { Navarro }\end{array}$ & 359 a 420 & 62 & $14.62 \%$ & $17.69 \%$ & $\$ 46.19$ & $0.55 \%$ & $5.19 \%$ \\
\hline Varios & & 421 a 424 & 4 & $0.94 \%$ & & $\$ 260.00$ & $3.11 \%$ & \\
\hline & & Totales & 424 & $100.00 \%$ & & $\$ 8372.59$ & $100.00 \%$ & \\
\hline
\end{tabular}

un "aderezo" -es decir, un juego de collar, pendiente y pulsera- "con treinta y nueve diamantes rosas, todo en oro" fue tasado en 70 pesos y el precio de un "terno" -un conjunto formado por collar, pendientes y alfiler- "de esmeraldas en oro, con dos almendras, los zarcillos de color" fue estimado en 80 pesos. Entre las pinturas del taller se mencionan "un lienzo de dos varas y ochava, con su marco dorado y copete y en él la imagen de Nuestra Señora de Guadalupe copiada puntualmente de la original", con valor de 80 pesos y una tabla de Teniers de 100 pesos. Memoria, descripción e inventario de los bienes que quedaron por fin y muerte de don Miguel de Cabrera. Ciudad de México, 26-V-1768 a 19-VIII-1768. Archivo Enrique A. Cervantes, sin signatura, ff. 6v-7 y 14v-15. Tovar de Teresa, 1995: 272-273 y 279.

28 Fuente: elaboración propia sobre Memoria, descripción e inventario de los bienes que quedaron por fin y muerte de don Miguel de Cabrera. Ciudad de México, 26-V-1768 a 19-VIII-1768. Archivo Enrique A. Cervantes, sin signatura, ff. 1-35. Tovar de Teresa, 1995: 269-293. Las filas en verde corresponden a los libros inventariados por Juan Patricio Morlete Ruiz y José Navarro. 
Tabla 2. Análisis cuantitativo de los libros pertenecientes a Miguel Cabrera ${ }^{29}$.

\begin{tabular}{|c|c|c|c|}
\hline \multicolumn{4}{|c|}{ Valor de los libros en relación con los bienes } \\
\hline Valor total de los bienes & 8372 pesos & & \\
\hline \multirow[t]{2}{*}{ Valor total de los libros } & 434.50 pesos & \multicolumn{2}{|c|}{$5.19 \%$ sobre el valor total de los bienes } \\
\hline & Número de inv & Títulos & Volúmenes \\
\hline $\begin{array}{l}\text { Libros de pintura valuados } \\
\text { por Patricio Morlete }\end{array}$ & 200 a 212 & 13 & 17 en folio \\
\hline \multirow[t]{2}{*}{$\begin{array}{l}\text { Libros valuados por José } \\
\text { Navarro }\end{array}$} & 359 a 420 & 62 & 67 en folio, $4^{\circ} 8^{\circ}$ y $16^{\circ}$ \\
\hline & Total & 75 & 84 \\
\hline \multicolumn{4}{|c|}{ Valor de los libros en relación con el formato } \\
\hline Volúmenes en folio & 23 & entre 1.5 y 51.5 pesos & \\
\hline Volúmenes en $4^{\circ}$ & 20 & entre 1 real y 5 pesos & \\
\hline Volúmenes en $8^{\circ}$ y $16^{\circ}$ & 41 & entre 1 real y 1 peso & \\
\hline
\end{tabular}

Ahora bien, aunque resulta importante cuantificar el inventario, sobre todo es necesario examinar su contenido. Al igual que la mayoría de sus colegas desde el siglo XVI, Miguel Cabrera tuvo además de libros impresos colecciones de grabados. Unos diez volúmenes encuadernados reunían más de mil estampas que nutrieron el repertorio iconográfíco del pintor. Si se ensayara ordenar su biblioteca de acuerdo con las orientaciones temáticas indicadas por Armenini o Palomino resulta claro que la mayor parte de los libros que poseyó Cabrera se relacionaron con la "historia sagrada": Biblias, vidas de santos y, sobre todo, sermones y tratados devocionales jesuitas; además de las obras clave sobre la Virgen de Guadalupe. Sólo un libro podría ser considerado como literatura profana. Además de los diez volúmenes de estampas, Cabrera sólo tenía tres obras especializadas sobre la práctica de la pintura en sus aspectos teóricos y técnicos; aunque buena parte de los libros religiosos pudieran estar vinculados al ejercicio de su profesión, así lo atestiguan los múltiples encargos que su taller cubrió no sólo en la capital virreinal, sino en las ciudades más importantes de Nueva España ${ }^{30}$ (Tabla 3).

29 Fuente: Elaboración propia sobre Memoria, descripción e inventario de los bienes que quedaron por fin y muerte de don Miguel de Cabrera. Ciudad de México, 26-V-1768 a 19-VIII-1768. Archivo Enrique A. Cervantes, sin signatura, ff. 1-35. Tovar de Teresa, 1995: 269-293.

30 Abelardo Carrillo y Gariel y luego Guillermo Tovar de Teresa realizaron los primeros estudios sobre Miguel Cabrera. Carrillo y Gariel, 1966; Tovar de Teresa, 1995. En este sentido es necesario profundizar desde nuevos enfoques el estudio de la obra del pintor, sobre todo desde el estudio de su biblioteca. Sobre todo, es necesario actualizar el catálogo de obras del pintor. 
Tabla 3. Libros sobre teoría y práctica de la pintura que poseía Manuel Cabrera ${ }^{31}$.

\begin{tabular}{|c|c|}
\hline $\begin{array}{l}\text { 200. Item, por un libro de a folio en pasta, su } \\
\text { autor Bandiquen en } 40 \text { pesos [f. 13v] }\end{array}$ & $\begin{array}{l}\text { Antonio van Dyck. Icones principum, virorum } \\
\text { doctorum pictorum. Amberes: Gillis Hendricx, } \\
\text { 1645. } 110 \text { grabados, folio }\end{array}$ \\
\hline \multicolumn{2}{|l|}{$\begin{array}{l}\text { 201. Item, una Biblia estampada, en dos tomos } \\
\text { de a folio, en pasta, en setenta pesos [f. 13v] }\end{array}$} \\
\hline \multicolumn{2}{|l|}{$\begin{array}{l}\text { 202. Item, un libro en pasta de mas de a cuarto, } \\
\text { con ciento y cincuenta estampas de varias } \\
\text { figuras, estantes y demas, en dieciocho pesos } \\
\text { seis reales [f. } 13 \mathrm{v}]\end{array}$} \\
\hline \multicolumn{2}{|l|}{$\begin{array}{l}\text { 203. Item, otro dicho de mas de folio, } \\
\text { encuadernado en pergamino doble, con ciento } \\
\text { veintiseis estampas, en veinticinco pesos [f. } 13 \mathrm{v}]\end{array}$} \\
\hline \multicolumn{2}{|l|}{$\begin{array}{l}\text { 204. Item, otro dicho de poco mas de cuarta, de } \\
\text { maquinas, forrado en pergamino, con treinta y } \\
\text { ocho estampas, en siete pesos [f. 14] }\end{array}$} \\
\hline \multicolumn{2}{|l|}{$\begin{array}{l}\text { 205. Item, otro dicho de a folio, con varias frutas } \\
\text { y otras estampas que todas hacen ciento y una, } \\
\text { de media pasta, en dieciocho pesos [f. 14] }\end{array}$} \\
\hline $\begin{array}{l}\text { 206. Item, dos tomos de a folio en pasta blanca, } \\
\text { de perspectivas, del padre Pozo, en cincuenta y } \\
\text { cinco pesos [f. 14] }\end{array}$ & $\begin{array}{l}\text { Andrea Pozzo. Perspectiva pictorum et } \\
\text { architectorum Andreae Putei, } 2 \text { volúmenes. } \\
\text { Roma: J.J. Komarek, 1693-1700. Folio. }\end{array}$ \\
\hline \multicolumn{2}{|l|}{$\begin{array}{l}\text { 207. Item, una Biblia de a folio en pasta blanca, } \\
\text { con doscientas diez fojas y en cada una cuatro } \\
\text { estampas, en treinta pesos [f. 14] }\end{array}$} \\
\hline \multicolumn{2}{|l|}{$\begin{array}{l}\text { 208. Item, un libro de a folio en pasta blanca } \\
\text { con ochenta estampas, en ocho pesos [f. 14] }\end{array}$} \\
\hline \multicolumn{2}{|l|}{$\begin{array}{l}\text { 209. Item, otro dicho de a folio en pasta blanca, } \\
\text { con ciento sesenta y tres estampas en veinticinco } \\
\text { pesos [f. 14] }\end{array}$} \\
\hline $\begin{array}{l}\text { 210. Item, dos tomos de obras de Palomino en } \\
\text { quince pesos [f. 14] }\end{array}$ & $\begin{array}{l}\text { Antonio Palomino de Castro y Velasco. El } \\
\text { museo pictorico y escala optica, T. I. Theorica } \\
\text { de la pintura. T. II. Practica de la pintura. } \\
\text { Madrid: Lucas Antonio de Bedmar, } 1715 \text {. Folio }\end{array}$ \\
\hline $\begin{array}{l}\text { 211. Item, dos libros en pasta, con todas las } \\
\text { estampas del año, que hacen trescientos sesenta } \\
\text { y seis, en veinticinco pesos [f. 14] }\end{array}$ & \\
\hline
\end{tabular}

31 Fuente: elaboración propia sobre Memoria, descripción e inventario de los bienes que quedaron por fin y muerte de don Miguel de Cabrera. Ciudad de México, 26-V-1768 a 19-VIII-1768. Archivo Enrique A. Cervantes, sin signatura, ff. 1-35. Tovar de Teresa, 1995: 269-293. Excepto el caso de los grabados de Van Dyck, las colecciones de estampas son muy difíciles de identificar. Un estudio en profundidad de la obra del pintor permitiría deducir algunas de las colecciones. 


\begin{tabular}{|c|c|}
\hline $\begin{array}{l}\text { 212. Item, varios estados de distintas estampas, } \\
\text { en los que se contienen el numero y precio, en } \\
\text { cincuenta y un pesos, cuatro y medio reales [f. } \\
\text { 14] }\end{array}$ & \\
\hline $\begin{array}{l}\text { 383. Item, otro dicho en octavo: Barqui, Sobre } \\
\text { la escultura y la pintura, en dos reales [f. } 20 \mathrm{f}]\end{array}$ & $\begin{array}{l}\text { Benedetto Varchi. Leccion que hizo Benedicto } \\
\text { Varqui en la Academia Florentina (...) sobre la } \\
\text { primacia de las artes, y qual sea mas noble, la } \\
\text { escultura ó la pintura con una carta de Michael } \\
\text { Angelo Buonarroti y otras de los mas célebres } \\
\text { pintores y escultores, trad. Felipe de Castro. } \\
\text { Madrid: Eugenio Bieco, } 1753 \text {. }\end{array}$ \\
\hline
\end{tabular}

Sin duda, las dos Biblias clasificadas dentro de los "libros tocantes a la pintura", son un claro ejemplo en este sentido. Muy probablemente se tratara de costosas ediciones ilustradas ${ }^{32}$. La primera de ellas, "una Biblia estampada, en dos tomos de a folio, en pasta", cuyo valor se estimó en 70 pesos, fue el libro más costoso del inventario. Quizá, podría identificarse como la Physica Sacra de Johann Jakob Scheuchzer. Se trata de una extensa obra publicada en cuatro volúmenes en folio, con 758 calcografías de extraordinaria calidad impresas a página completa. Johann Andreas Pfeffel estuvo a cargo de la edición y en ella participaron grabadores como Corvinus, Fridrich, Sperling y Linz. El contenido es igualmente sorprendente: a través de una intrincada argumentación, el autor mezcla la historia sagrada y la filosofía natural. Los grabados representan tanto escenas de pasajes bíblicos, como fósiles, plantas y animales con todo detalle ${ }^{33}$. La segunda, "una Biblia de a folio en pasta blanca, con doscientas diez fojas y en cada una cuatro estampas", se tasó en 30 pesos. Que ambas estuvieran en manos de un pintor del siglo XVIII es tan sugestivo para la historia del arte como para la historia del libro. Aquellas obras producto del arte de la impresión -posiblemente atesoradas-se nutrieron del arte de la pintura y a su vez lo enriquecieron, así como fueron también objetos de colección. De igual modo, este dato deja testimonio de la vigencia y la circulación de las Biblias ilustradas más allá del siglo XVI.

Otro libro mencionado en el inventario descubre algunos intereses de Miguel Cabrera como pintor sobre los que es necesario profundizar. Patricio Morlete Ruiz registró "un libro de a folio en pasta, su autor Bandiquen" cuyo valor fijó en 40 pesos. Con seguridad se trató de la obra de Antoon Van Dyck, Icones principum, virorum doctorum pictorum, impresa en 1646. También conocida como Iconographia, fue una edición póstuma de 100 retratos realizados por Van Dyck y grabados por Lucas Vorsterman y Paulus Pontius ${ }^{34}$. Es posible que fuera el mismo ejemplar que aparece en el

32 Las Biblias en imágenes y las Biblias ilustradas no fueron excepcionales entre los siglos XVI y XVIII. Torres Santo Domingo, 2014: 186-187.

33 Scheuchzer, 1731, 1732, 1733 y 1735. Tal vez Cabrera pudo tener sólo dos tomos. Podría especularse también que tuviera las láminas encuadernadas. Actualmente, en la ciudad de México, en una colección privada, se conservan parte de los grabados de la obra de Scheuchzer encuadernados en dos volúmenes.

34 Van Dyck, 1646. Estos grabados se organizan en grupos. En primer lugar, los príncipes y gobernantes; después los ministros y humanistas; y, en tercer lugar, los artistas y aficionados al arte. Se ha indicado que, pese a que la mayoría de estos retratos habían aparecido antes de la muerte de Van Dyck (1641), la selección de los retratados fue hecha por su editor, Martin Van Enden, y puede ser que no refleje la voluntad del pintor. Cacho Casal, 2011: 138; Mauquoy-Hendrickx, 1991; Spicer, 1994: 326-356. 
avalúo de bienes pertenecientes a José de Ibarra ${ }^{35}$. Quizá Cabrera lo adquiriera en la almoneda de los bienes de su maestro - una práctica muy frecuente que es esencial para comprende la circulación de los libros ${ }^{36}$. El interés en esta colección de grabados se puede vincular con dos aspectos de su trabajo como pintor. Por un lado, su abundante producción como retratista. Además de las imágenes de virreyes y damas nobles que se conservan, de acuerdo con el inventario, al momento de su muerte, había en el taller al menos cuatro retratos de entre 1 y 2 varas $(83.5$ y $167 \mathrm{~cm})$, además de otros 120 posiblemente de menor tamaño ${ }^{37}$. Por otro lado, aquel libro documenta su interés en la pintura flamenca del siglo XVII. Junto con la colección de grabados de Van Dyck, de acuerdo con el mismo inventario, el cuadro más costoso que poseía Cabrera, valuado en 100 pesos, era "un juego de naipes", de menos de una vara $(83.5 \mathrm{~cm})$, de David Teniers (1610-1690) $)^{38}$. Posiblemente se trate de una de las tantas escenas de tabernas y bebedores, temas costumbristas que todavía en el siglo XVIII fueron objeto de colección ${ }^{39}$.

Paradójicamente, y más allá de los diez volúmenes de estampas, podrían sorprender los escasos libros sobre pintura que poseyó Cabrera. El inventario registró sólo tres: la Lección sobre la primacía de las artes de Benedetto Varchi, la Perspectiva del Padre Andrea Pozzo y los dos primeros tomos de El museo pictórico y escala óptica de Antonio Palomino. Ahora bien, la obra de Benedetto Varchi no se encontraba entre sus libros de taller, apareció en el listado de impresos tasado por José Navarro y por tanto quizá formara parte de los libros que se hallaron en el estudio. Las reflexiones del humanista florentino sobre el arte -que habían sido publicadas en 1549- recogían las dos lecciones pronunciadas por él en la Academia de Florencia ${ }^{40}$. La primera consistía, básicamente, en una alabanza a Miguel Ángel. La segunda discurrió sobre el tema del "parangón", una cuestión ampliamente debatida en la teoría del arte del siglo XVI que se extendió hasta el XVIII. En ella la semejanza de la pintura y la poesía en cuanto a sus fines -la imitación de la naturaleza de acuerdo con las reglas del arte- fue el punto de partida para iniciar una reflexión sobre la rivalidad entre la pintura y la escultura, que contempló el examen de las posibilidades y los límites de sus respectivos medios en función del vínculo de ambas con las artes liberales. Varchi apeló a un recurso humanista: so-

35 Las referencias parciales sobre el inventario de los libros que José de Ibarra poseía fueron anotadas por Myrna Soto. En marzo de 1756, tras la muerte de su padre, José Antonio de Ibarra inició el trámite para el avalúo de los bienes del pintor. El documento relativo a la testamentaría procede del Archivo Enrique A. Cervantes. Myrna Soto llama la atención sobre algunos de los títulos, entre ellos señala el libro de estampas de Van Dyck, cuyo precio fue fijado en 20 pesos. Soto, 2005: 87-92. Paula Mues Orts hizo observaciones puntuales sobre el problema de la localización del documento. Mues Orts, 2009: 220.

36 Sobre la dificultad y la complejidad de rastrear las múltiples vías de circulación de los libros en Nueva España: García Aguilar, 2013: 19-39.

37 Memoria, descripción e inventario de los bienes que quedaron por fin y muerte de don Miguel de Cabrera. Ciudad de México, 26-V-1768 a 19-VIII-1768. Archivo Enrique A. Cervantes, sin signatura, ff. 6-11. Tovar de Teresa, 1995: 272-276.

38 "21. Item, otro dicho de menos de vara, con Juego de Naipes, y marco negro, de mano de David Theniers, en cien pesos", Ibídem, f. 7. Tovar de Teresa, 1995: 273.

39 El Museo Nacional del Prado conserva al menos seis cuadros de David Teniers sobre escenas de tabernas con bebedores, fumadores y jugadores, estas pinturas pertenecieron a la colección de Isabel Farnesio y están documentadas en el inventario de 1766. Esto demuestra el interés que la obra de Teniers tuvo para los grandes coleccionistas del siglo XVIII. Disponible en https://www.museodelprado.es/index.php?id=995\&no_cache=1 $\& \mathrm{~L}=0 \& \mathrm{cHash}=38 \mathrm{c} 550 \mathrm{c} 57 \mathrm{c} \&$ gbobras $\% 5 \mathrm{Badv} \% 5 \mathrm{D}=0 \&$ gbobras $\% 5 \mathrm{Bcriterio} \% 5 \mathrm{D}=1 \&$ gbobras $\% 5 \mathrm{Bstring} \% 5 \mathrm{D}$ $=$ Teniers $\% 2 \mathrm{C}+$ David

$40 \quad$ Varchi, 1549. 
bre la base de siete tópicos fundamentales relacionados con el tema, recogió el testimonio de los más célebres artistas de Florencia ${ }^{41}$. Fue precisamente esta segunda lección, que tradujera al castellano Felipe de Castro en el ambiente de los debates en torno a las academias durante el siglo XVIII, la que poseyó Miguel Cabrera ${ }^{42}$. Su interés en las reflexiones de Varchi podrían interpretarse como un indicio de sus inquietudes teóricas, así como de sus preocupaciones sobre el estatus liberal de la pintura, la posición social del artista y la formación de círculos académicos en la capital virreinal ${ }^{43}$.

El segundo libro que poseyó Cabrera, ligado de manera directa con la práctica de la pintura, fue la Perspectiva pictorum et architectorum del jesuita Andrea del Pozzo. Se trató de una obra bilingüe -en latín e italiano- concebida, en sentido estricto, como una iniciación a los fundamentos del dibujo arquitectónico en perspectiva. Con varias ediciones durante el siglo XVIII, podría decirse que fue un libro sobre arquitectura destinado a los pintores ${ }^{44}$. De acuerdo con Pozzo un buen pintor debía ser un gran conocedor de la perspectiva y en consecuencia también un buen arquitecto ${ }^{45}$. La obra ofreció tanto los elementos básicos para dominar las técnicas de proyección, como un repertorio con composiciones de escenarios arquitectónicos muy útiles para los pintores. En la biblioteca de Cabrera, el tratado de Pozzo parece cubrir los campos de conocimiento recomendados tanto por Armenini como por Carducho y más tarde enfatizados precisamente por Antonio Palomino. Por otro lado, es esta misma tradición textual la que permite explicar por qué también el pintor novohispano tuvo un ejemplar de la Anatomía completa del hombre de Martín Martínez ${ }^{46}$. Inscrito dentro del movimiento de renovación de la medicina a principios del siglo XVIII, el tratado del médico y anatomista cercano a Felipe V sintetizó las novedades morfológicas y fisiológicas aportadas por la "medicina escéptica" -una nueva orientación en la que la observación clínica confluía con la anatomía y la fisiología experimental ${ }^{47}$. El libro contó con nueve ediciones y es posible especular que Cabrera estuviera interesado, de manera general, en los grabados de Matías de Irala Yuso, más que en el

41 Schlosser, 1993: 203-211; Garriga, 1983: 245-254; Hellwing, 1999: 175-252; Hellwig, 2012: 223-238.

42 El registro "383. Item, otro dicho en octavo: Barqui, Sobre la Escultura y la Pintura, en dos reales" puede identificarse como Benedetto Varchi, 1753. Memoria, descripción e inventario de los bienes que quedaron por fin y muerte de don Miguel de Cabrera. Ciudad de México, 26-V-1768 a 19-VIII-1768. Archivo Enrique A. Cervantes, sin signatura, f. 20. Tovar de Teresa, 1995: 284. Dado que el título en el documento está registrado en español es más probable que Cabrera tuviera la traducción impresa en 1753 que la edición original en italiano de 1549 .

43 Durante la primera mitad del siglo XVIII puede rastrearse el surgimiento de grupos de pintores con intereses en la formación de una academia. En 1722 algunos artistas se reunían en torno a los pintores Nicolás y Juan Rodríguez Juárez. Tovar de Teresa, 1988: 104-105; Soto, 2005: 42-43; Mues Orts, 2008: 239-317; Rodríguez Moya, 2006: 34-55; Báez Macías, 2009: 21-22. Décadas más tarde, en 1754, José de Ibarra presidía "la sociedad y academia del nobilísimo arte de la pintura", formada por un grupo de artistas que se congregaban dos veces por semana para "mejor instruirse [...] mediante la corrección de unos y otros y de los mayores a los menores con arreglamiento y doctrina de los autores y suscritores”. Moyssén: 1965: 15-29.

44 Además de la primera edición en Roma, 1693-1700, la obra fue publicada en 1702, 1717, 1723, $1764,1768$. Schlosser, 1993: 530-531.

$45 \quad$ Kruft, 1985: 138-139.

46 El registro "371. Item, otro dicho: Martínez Anatomía completa, en cinco pesos" puede identificarse como Martin Martinez, 1728. Memoria, descripción e inventario de los bienes que quedaron por fin y muerte de don Miguel de Cabrera. Ciudad de México, 26-V-1768 a 19-VIII-1768. Archivo Enrique A. Cervantes, sin signatura, f. 20. Tovar de Teresa, 1995: 283.

47 López Piñero, 1987: 86-87. 
contenido especializado, tal y como había recomendado Carducho a principios del siglo XVII ${ }^{48}$.

Quizá los libros clave en la biblioteca del pintor novohispano sean los dos tomos de El museo pictórico y escala óptica. La erudita obra de Antonio Palomino contribuyó de manera sustantiva a la sistematización de una parte de la teoría artística del siglo XVIII en el ámbito hispánico. Un indicio de su amplia recepción es la reedición a finales del siglo y la traducción del tomo III al inglés, francés y alemán ${ }^{49}$. Concebido sobre la base de la compilación de las ideas artísticas del siglo XVII, resultó ser un tratado histórico y teorético, fundado en una vasta erudición y organizado como un curso completo para la formación académica del pintor ${ }^{50}$. Por tanto, analizado en profundidad, en principio podría ser una pieza fundamental para un acercamiento al modo de pintar del artista novohispano, en relación con una indagación sobre sus formas de leer.

En consecuencia, si bien Cabrera poseía sólo tres libros específicos sobre arte, los tres permiten sospechar que estuvo familiarizado, o al menos preocupado, por las ideas y los debates artísticos de su tiempo. Asimismo, los tres pueden relacionarse de otras maneras con el pintor y con su obra, además arrojan luz sobre la situación de la pintura hacia mediados del siglo XVIII en Nueva España, momento en el que algunos artistas pugnaron por la fundación de una academia ${ }^{51}$. En este contexto tres libros sobre pintura parecen muy poco para quien defendía la condición liberal de su disciplina. Sin embargo, Cabrera fue un artista que escribió y aunque su texto estuvo dirigido sobre todo a la demostración del carácter milagroso de la imagen de la Virgen de Guadalupe, la Maravilla americana es también un libro sobre la pintura ${ }^{52}$. En particular, un aspecto notable en él es su estructura argumental encaminada hacia un análisis "científico" de la imagen. Su texto, dividido en ocho partes, examinó la pintura de manera ordenada; comienza por la materialidad y la técnica, continúa por los aspectos compositivos - como el dibujo y el color- y, finalmente, pondera sus cualidades estéticas. A continuación, refuta los posibles argumentos en contra, para por último intentar probar que la imagen de la Virgen es una "obra de arte ejecutada por Dios", una obra "milagrosa" en cuanto a la técnica y a la inventio. Así, Cabrera demostró ser un lector atento de El museo pictórico y escala óptica. Si bien el tratado de Palomino conjugó los aportes de los grandes teóricos españoles del siglo XVII, uno de sus rasgos más característicos es su clara estructura en función de una exposición rigurosa, precisa y sistemática. Producto de una vasta cultura artística y de una estricta formación tomista, Palomino consideró que "sólo hay un ordenado modo de proceder en la investigación de la verdad", a la que únicamente se puede acceder "inquiriendo la esencia; dividiendo sus especies y examinando sus propiedades"; asumió por tanto, las tres operaciones lógicas de definir, dividir y argumentar ${ }^{53}$. Sobre la base de estos presupuestos organizó todos sus razonamientos con el fin de

48 Véase nota 12.

49 Además de la primera edición de 1715-1724, los tres tomos fueron reimpresos en 1795-1797. El tomo III, una colección de biografía de artistas desde el siglo XVI, tuvo una edición en inglés (Londres, Harding, 1739), en francés (París, Chez Delaguette, 1749) y alemán (Dresden, Hilscher, 1781). Schlosser, 1993: 429.

50 Ibídem: 409-410; Morán Turina - Portús Pérez, 1997: 175-194.

51 Véase nota 40.

52 Cabrera, 1756. Los más recientes aportes sobre Maravilla americana de Miguel Cabrera y los debates en torno a la condición liberal de la pintura en Nueva España han sido realizados por Cuadriello - Mues Orts - Granados Salinas, 2001; Mues Orts, 2008.

53 Moran Turina - Portús Pérez, 1997: 176. 
exponer que la cualidad esencial de la pintura era ser ciencia demostrativa en lo teórico y práctica en lo operativo ${ }^{54}$. Cabrera utilizó esta estructura argumental para analizar una pintura y, paradójicamente, demostrar de manera "científica" su carácter milagroso y divino. Argumentó la condición milagrosa de la imagen a través de un detallado examen de sus cualidades técnicas: desde la preparación y los materiales hasta la excepcional "combinación de especies de pinturas". Pero sobre todo resaltó que el diseño sería el producto de una inventio superior. De forma ordenada y sistemática, siguiendo de manera general la estructura analítica de Palomino, utilizó los fundamentos de la teoría del arte, con la intención de demostrar el carácter sobrenatural de la imagen religiosa. La Maravilla americana revela a un artista conocedor de los fundamentos teóricos de la pintura (Tabla 4).

Tabla 4. Comparación de la estructura argumental del tratado de Palomino y la obra de Miguel Cabrera ${ }^{55}$.

\begin{tabular}{|c|c|c|c|}
\hline \multicolumn{2}{|c|}{$\begin{array}{l}\text { Antonio Palomino de Castro y Velasco. } \\
\text { El museo pictorico y escala optica. Madrid: } \\
\text { Lucas Antonio de Bedmar, } 1715 \text {. }\end{array}$} & \multicolumn{2}{|c|}{$\begin{array}{l}\text { Miguel Cabrera. Maravilla americana y } \\
\text { conjunto de raras maravillas. México: Real } \\
\text { Colegio de San Ildefonso, } 1756 .\end{array}$} \\
\hline \multirow{3}{*}{$\begin{array}{l}\text { Tomo I } \\
\text { Theorica de } \\
\text { la pintura. }\end{array}$} & $\begin{array}{l}\text { Libro I: El aficionado } \\
\text { Qué es la pintura, su origen }\end{array}$ & I. & $\begin{array}{l}\text { Maravillosa duracion de la Imagen de } \\
\text { nuestra Señora de Guadalupe }\end{array}$ \\
\hline & $\begin{array}{l}\text { Libro II: El curioso } \\
\text { La liberalidad de la pintura y sus } \\
\text { especies }\end{array}$ & & $\begin{array}{l}\text { De la tela, o lienzo en que está pintada } \\
\text { nuestra Señora de Guadalupe }\end{array}$ \\
\hline & $\begin{array}{l}\text { Libro III: El Diligente } \\
\text { El carácter científico de la } \\
\text { pintura }\end{array}$ & \multirow[t]{2}{*}{$\begin{array}{l}\text { III. } \\
\text { IV. }\end{array}$} & De la falta de aparejo en esta pintura \\
\hline \multirow{6}{*}{$\begin{array}{l}\text { Tomo II } \\
\text { Practica de } \\
\text { la pintura }\end{array}$} & $\begin{array}{l}\text { Libro IV: El principiante } \\
\text { La formación inicial del pintor }\end{array}$ & & Señora de Guadalupe \\
\hline & $\begin{array}{l}\text { Libro V: El copiante } \\
\text { El estudio de los modelos }\end{array}$ & \multirow{3}{*}{$\begin{array}{l}\text { V. } \\
\text { VI. }\end{array}$} & $\begin{array}{l}\text { De quatro especies de pinturas, que } \\
\text { concurren maravillosamente en la Imagen } \\
\text { de nuestra Señora de Guadalupe }\end{array}$ \\
\hline & $\begin{array}{l}\text { Libro VI: El aprovechado } \\
\text { La composición del natural }\end{array}$ & & Del precioso oro, y esquisito dorado de la \\
\hline & $\begin{array}{l}\text { Libro VII: El inventor } \\
\text { La inventio }\end{array}$ & & $\begin{array}{l}\text { Milagrosa Imagen de nuestra Señora de } \\
\text { Guadalupe }\end{array}$ \\
\hline & $\begin{array}{l}\text { Libro VIII: El práctico } \\
\text { Aspectos técnicos }\end{array}$ & \multirow[t]{2}{*}{ VII. } & $\begin{array}{l}\text { En que se destacan las objeciones, que } \\
\text { han opuesto a nuestra bellissima Pintura }\end{array}$ \\
\hline & $\begin{array}{l}\text { Libro IX: El perfecto } \\
\text { La formación intelectual del } \\
\text { pintor }\end{array}$ & & $\begin{array}{l}\text { Disseño de la milagrosa Imagen de } \\
\text { nuestra Señora de Guadalupe }\end{array}$ \\
\hline
\end{tabular}

54 Ibídem: 176.

55 Fuente: elaboración propia sobre Palomino, 1715; Cabrera, 1756. Los colores señalan de manera general las correspondencias entre ambas obras y la relación entre inventio y técnica. 
En igual medida, la biblioteca de Cabrera revela que fue un artista tan práctico como teórico y un lector agudo de Palomino, quien a lo largo de su tratado en distintas partes insistió en la necesidad de que el verdadero pintor procurara una formación intelectual que abarcara los diversos campos del conocimiento requeridos por su quehacer. En reiteradas oportunidades señaló la importancia de que los artistas fueran hombres de medianas letras y recordó que "los pintores eruditos, especialmente inventores, tienen pieças separadas, que llaman estudio, donde están los libros, papeles, y modelos; y donde se retiran a especular, e inventar lo que se les ofreçe" ${ }^{\text {" }}$. También insistió en que "siempre que el Pintor aya de executar alguna obra insigne, y de grande empeño, procure tener del assunto plenissima noticia; porque de otro

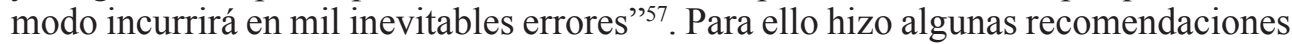
bibliográficas puntuales. El pintor de historias sagradas debía tener y estudiar la Biblia, revisar el Flos Sanctorum, la vida de Cristo, de la Virgen y de los santos. Dentro de esta orientación temática muy general señalada por Palomino, la biblioteca de Cabrera fue precisa y especializada: tuvo los tratados sobre la Virgen de Guadalupe y las obras devocionales jesuitas -dos campos claramente relacionados con su actividad profesional y con sus principales patronos-, además de la Biblia -en dos ediciones ilustradas. Así, los tres escritos clave sobre la devoción guadalupana-Felicidad de México de Luis Becerra Tanco, La estrella del norte de Francisco de Florencia y Escudo de Armas de Cayetano Cabrera y Quintero ${ }^{58}$ - confirman la profunda actitud analítica que subyace en la Maravilla americana y que puede vincularse con la lectura y la recepción de las ideas de Palomino. Sin duda son sintomáticos de la continua retroalimentación entre la profusa y rica iconografía guadalupana y las reflexiones teológicas y devocionales que acompañaron el culto mariano ${ }^{59}$. Aún más, una de las Biblias también podría relacionarse con el interés científico y religioso alentado por Palomino, patente en el escrito de Cabrera sobre la Virgen de Guadalupe ${ }^{60}$.

En tanto que uno de los grandes clientes del taller de Miguel Cabrera fue la Compañía de Jesús - para la que pintó dos series de la vida de su fundador- resulta importante tener en cuenta que entre sus libros se encontraba la Vida, virtudes, $y$ milagros de San Ignacio de Loyola del jesuita Francisco García ${ }^{61}$. La primera serie,

56 Palomino, 1715, t. I: 72.

57 Ibídem, t. II: 139.

58 El registro "359. Item, por un tomo de a folio de Cabrera, Escudo de Armas de Mexico, en doce reales" puede identificarse como Cabrera y Quintero, 1746. La anotación "368. Item, otro dicho: Florencia, la Estrella del Norte, en cuatro reales" corresponde seguramente a Francisco de Florencia, 1741. Finalmente, "395. Item, otro dicho: Becerra Tanco, Felicidad de México, en cuatro reales" se refiere a Luis Becerra Tanco, 1685. Memoria, descripción e inventario de los bienes que quedaron por fin y muerte de don Miguel de Cabrera. Ciudad de México, 26-V-1768 a 19-VIII-1768. Archivo Enrique A. Cervantes, sin signatura, ff. 19v-20 v. Tovar de Teresa, 1995: 283-284.

59 Un avance sustantivo en cuanto al estudio de los múltiples vínculos entre iconografía, pintura y los tratados teológicos y devocionales sobre la imagen de la Virgen de Guadalupe se encuentra en Cuadriello, 2001.

60 Véanse notas 29 y 30.

61 “377. Item, otro dicho: García, Vida de San Ignacio, en doce reales” puede identificarse como García, 1685. Memoria, descripción e inventario de los bienes que quedaron por fin y muerte de don Miguel de Cabrera. Ciudad de México, 26-V-1768 a 19-VIII-1768. Archivo Enrique A. Cervantes, sin signatura, f. 20. Tovar de Teresa, 1995: 283-284. El libro de Francisco García fue reimpreso en Madrid, Gregorio Hermosilla, 1722. La importancia de esta obra, en relación con las dos series de la vida de San Ignacio pintadas por Miguel Cabrera, ha sido claramente señalada por Verónica Aurelia Zaragoza Reyes. A partir del análisis de las pinturas y algunos pasajes específicos de la biografía ella demuestra que en gran medida las variaciones iconográficas introducidas por Cabrera se relacionaron con el texto del jesuita. Asimismo, hace evidente la recepción que el libro de García tuvo durante el siglo XVIII en Nueva España. Zaragoza Reyes, 2012: 141-274. 
compuesta por 33 lienzos de gran formato y destinada para la Casa Profesa de la ciudad de México, fue realizada en 1756, la segunda, para el colegio de San Ignacio de la ciudad de Querétaro ${ }^{62}$. Una de las características más notables en la narrativa visual de Cabrera sobre la vida del santo es su distanciamiento del modelo tradicional proporcionado por los grabados de Rubens y Jean-Baptiste Barbé -impresos en $1609^{63}$. Por ejemplo, en la primera pintura de la serie para la Casa Profesa, que corresponde a la escena del nacimiento de San Ignacio, Cabrera no recurrió al tópico hagiográfico de acuerdo con el cual el santo habría nacido en un pesebre y situó la escena en un interior suntuoso con detalles -como un gran reloj- que evocan una habitación noble del siglo XVIII. Así parece retomar una reflexión de García, quien tras ponderar largamente los antecedentes genealógicos y la nobleza de la familia señala:

Escriven, que San Ignacio naciò en un establo, por devocion de su madre, y providencia Divina, para que naciesse como Jesus, el que avia de ser imitador de Jesus, y Alferez de su Compañia. Pero yo, ni me atrevo à firmarlo, porque no encuentro fundamento de la solidèz que yo quisiera para la verdad de mi historia, y menos puedo negarlo, por los muchos que lo afirman; especialmente aviendo salido en Roma el año de mil seisciento y nueve, con licencia de los Superiores de la Compañia una Vida de San Ignacio en Imagenes, en cuya primera estampa se dize: Mater Ignatium paritura, pro sua in Natalem Domini pietate, deferri se iubet in stabulum: eunque post septem filios postremum in stabulo parit: anno salutis $1491^{64}$.

De esta manera, Cabrera parece haber atendido a las dudas que García había expresado sobre la tradición textual y visual en la narración de la vida de San Ignacio. Aún más en una escena adjunta a la principal -que se desarrolla en segundo plano, hacia el fondo, en una habitación anexa- aparecen la venerable Angela Panigarola y el abad Joaquín de Fiore -identificados mediante la inscripción de sus nombres- quienes de acuerdo con García habrían profetizado la fundación de la Compañía de Jesús ${ }^{65}$. En consecuencia, Cabrera a través de la lectura fue capaz de "inventar" nuevas composiciones y renovar los esquemas iconográficos (Figura 1).

\footnotetext{
62 La serie de la Casa Profesa se encuentra actualmente en el Museo Nacional del Virreinato, la del colegio de San Ignacio en el Museo Regional de Querétaro. Carrilo y Gariel,1966: 34, 134 y 136-138; Tovar de Teresa, 1995: 340-342; Zaragoza Reyes, 2012: 141-274.

63 Gutiérrez Haces, 2007.

64 García, 1685: 23-24.

65 Ibídem: 7-9. Véase Zaragoza Reyes, 2012: 145-149.
} 

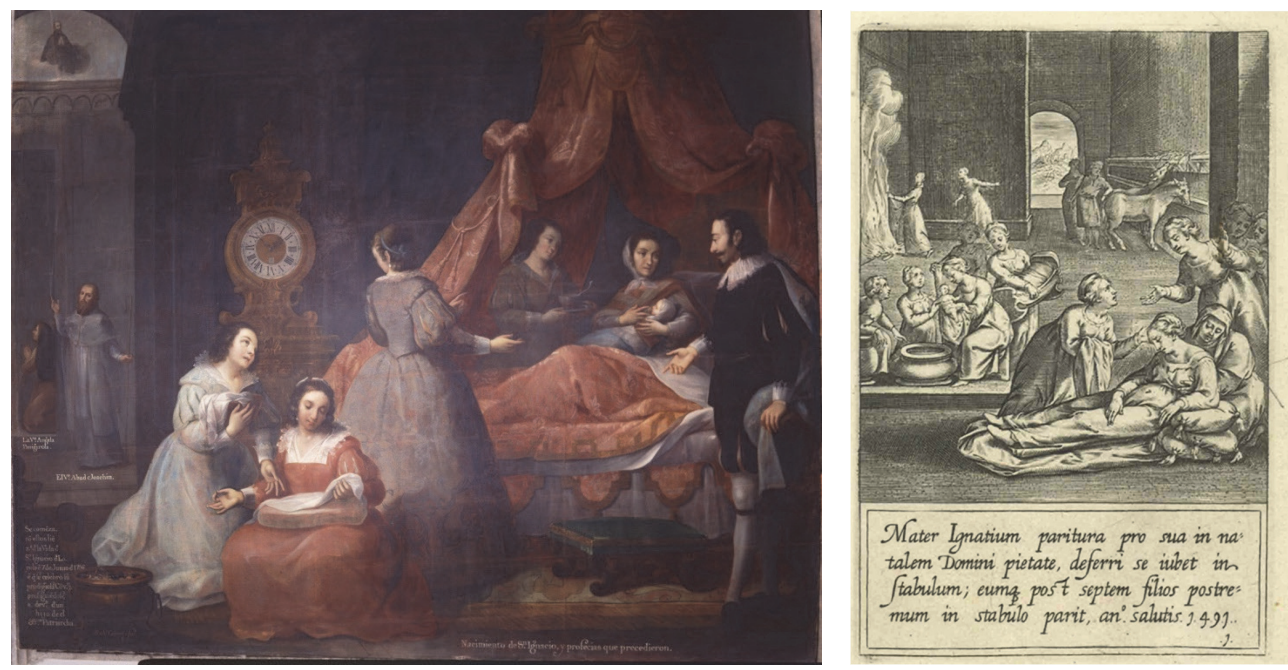

Figura 1. Miguel Cabrera recrea la vida de San Ignacio a partir de la narración de Francisco García y se aparta de la iconografía tradicional de Barbé y Rubens ${ }^{66}$.

La preocupación por documentarse acerca de los temas relacionados con sus principales encargos permitiría explicar también por qué, entre los impresos valuados por José Navarro, se encontraba un pequeño devocionario dedicado a Nuestra Señora de la Luz $^{67}$. A principios del siglo XVIII los jesuitas promovieron en Sicilia aquella nueva advocación de la Virgen. La imagen habría surgido de la aparición milagrosa de María a una mujer piadosa en Palermo y fue acompañada por la publicación de un extenso tratado en dos volúmenes acerca de la devoción. Escrito originalmente en italiano, fue traducido en México poco después ${ }^{68}$. El pequeño devocionario que poseyó Cabrera era una síntesis de aquella obra en el que se incluía la imagen grabada y se relataba el milagro de su creación; además contenía los ejercicios y las oraciones. Auspiciado por los jesuitas, el culto se extendió muy rápido por Nueva España, tanto en ámbitos urbanos como en las misiones del norte a partir de mediados del siglo XVIII. Cabrera pintó esta imagen en diferentes formatos y para diversos clientes. Un lienzo conservado en el Museo Nacional del Virreinato sin duda formó parte de un retablo, otro de tamaño reducido posiblemente perteneció a un espacio doméstico y privado. La atención que el pintor pudo poner al texto sobrepasa la fidelidad que sus pinturas tuvieron con respecto al grabado. Un rasgo peculiar como el gesto y la expresión de la Virgen, logrados por el tratamiento pictórico de la imagen, sin duda

${ }_{66}$ Fuente: Figura izquierda: Miguel Cabrera, Virgen de la Luz, mediados del siglo XVIII, óleo sobre tela, $103 \times 76$ $\mathrm{cm}$, Museo Nacional del Virreinato INAH, México. Figura derecha: Nacimiento de San Ignacio, de la serie de grabados de Jean-Baptiste Barbé y Peter Paul Rubens. Vita Beati P. Ignatii Loiolae Societatis Iesu Fundatoris. Roma, 1622.

67 "416. Item, otro dicho: Antidoto contra todo mal, en cuatro reales", puede ser identificado como Antídoto, 1737. Memoria, descripción e inventario de los bienes que quedaron por fin y muerte de don Miguel de Cabrera. Ciudad de México, 26-V-1768 a 19-VIII-1768. Archivo Enrique A. Cervantes, sin signatura, f. 21. Tovar de Teresa, 1995: 285 .

68 La divozione, 1733. Aunque el impreso fue publicado de manera anónima tradicionalmente se ha identificado al padre Giovanni Antonio Genovese (SJ) como su autor. Fue traducido en México: La devocion, 1737-1738. 
revela una atenta lectura y, al mismo tiempo, la habilidad de Cabrera para traducir al lenguaje visual las experiencias verbalizadas a través del escrito (Figura 2).
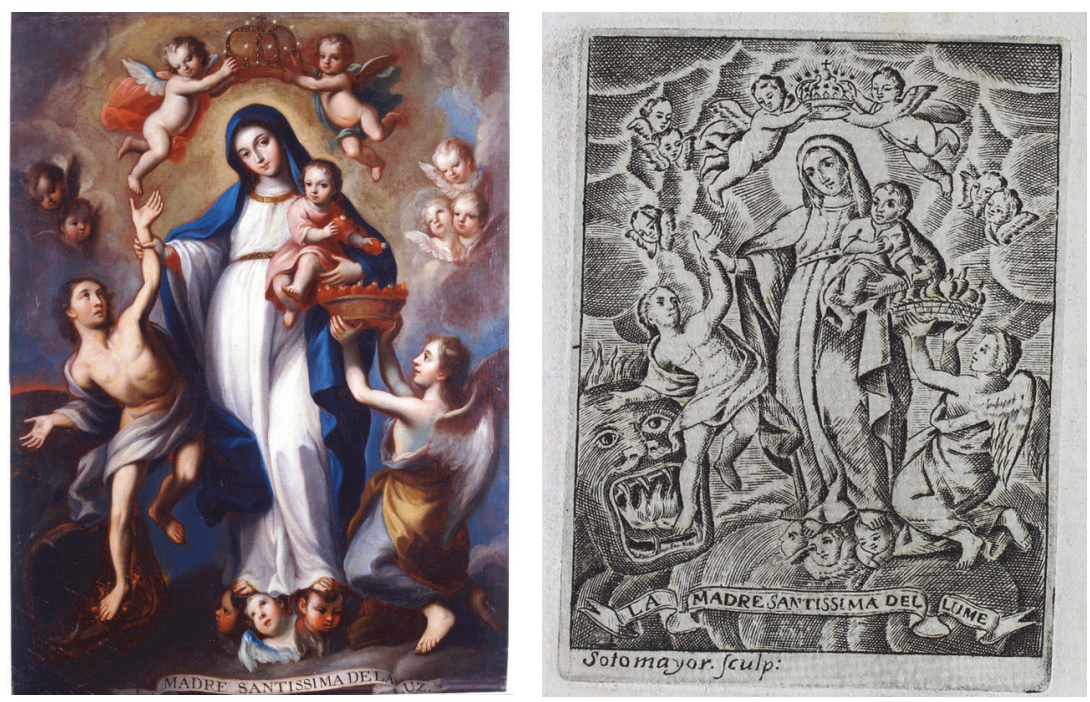

Figura. 2. Interpretación de la iconografía de la Virgen de la Luz a partir del grabado publicado en el tratado devocional ${ }^{69}$.

Asimismo, es necesario subrayar que el inventario registró entre los libros del pintor novohispano el tercer tomo de la Mística ciudad de Dios. La obra de sor María de Jesús se imprimió por primera vez en 1670, fue reeditada decenas de veces y traducida a distintos idiomas ${ }^{70}$. De las múltiples ediciones que circularon es posible deducir que Cabrera tuviera la edición en $8^{\circ}$, publicada en cuatro volúmenes, el año de $1723^{71}$. En este extenso tratado -que alcanzó una extraordinaria fortuna desde finales del siglo XVII, con profundas repercusiones en la iconografía novohispana del siglo XVIII- la célebre monja dejó testimonio de sus prodigiosas visiones místicas y desarrolló, a partir de la vida de la Virgen, los tópicos fundamentales de la doctrina inmaculista. Su argumentación combinó, mediante poderosas imágenes, la narración con la descripción de sus visiones; en consecuencia, el texto tiene un fuerte carácter

69 Fuente: Figura izquierda: Miguel Cabrera, Virgen de la Luz, mediados del siglo XVIII, óleo sobre tela, $103 \times 76$ $\mathrm{cm}$, Museo Nacional del Virreinato INAH, México. Figura derecha: Grabado de La devocion de Maria Madre Santissima de la Luz distribuida en tres partes por un Sacerdote de la Compañia de Jesus, traducido por Lucas Rincon (SJ), tomo 1. México: Imprenta Real del Superior Gobierno y del Nuevo Rezado de Doña María de Rivera, 1737.

70 María de Jesús de Ágreda, 1670 y 1723. Puede mencionarse también una edición completa, México: J. B. Hogal y J. Ignacio de Castorena y Ursua, 1731. Además de ocho ediciones abreviadas, seis con pie de imprenta en México, una en Puebla y una en Guatemala. México: José de San Antonio Flores, 1693; México: F. Rivera Calderón, 1717; México: J. B. del Hogal, 1730; México: Hogal, 1731; Puebla: Vda. de Ortega, 1749; Guatemala: Arévalo, 1761; México: sin impresor, 1763; México: F. de Zúñiga, 1784. Ver María de Jesús de Ágreda, 1985: CII-CV.

71 La anotación “387. Item, otro dicho: tomo tercero de la Madre Agreda, en cuatro reales" puede identificarse como María de Jesús de Ágreda, 1723. Memoria, descripción e inventario de los bienes que quedaron por fin y muerte de don Miguel de Cabrera. Ciudad de México, 26-V-1768 a 19-VIII-1768. Archivo Enrique A. Cervantes, sin signatura, f. 20v. Tovar de Teresa, 1995: 284. 
visual y ofrece un repertorio de tópicos narrativos enlazados con un sentido simbólico y trascendente que es posible rastrear en la pintura de Miguel Cabrera.

Por último, sólo un libro podría ser clasificado como literatura profana: la obra de José Rodríguez del Toro, Llanto de la fama reales exequias de la serenissima señora Doña María Amalia de Saxonia ${ }^{72}$. El impreso conmemoró las honras fúnebres celebradas en la capital virreinal a la esposa de Carlos III. Los grabados de José Eligio Morales, a partir de los dibujos de Miguel Cabrera, permiten rastrear los vínculos del pintor con el mundo de la literatura, la emblemática y la imprenta novohispana -campo de estudio sobre el que es necesario profundizar. Años más tarde también diseñó los monumentos para las exequias del arzobispo Manuel Rubio y Salinas y para los funerales de la reina Isabel de Farnesio. Ambos acontecimientos fueron recordados con dos impresos que incluyeron los grabados de las piras y sus jeroglíficos ${ }^{73}$. Podría decirse entonces que tanto aquellos libros de carácter religioso y devocional, como los relacionados con la literatura y la historia fueron leídos desde un interés profesional y en ese sentido podrían entenderse como libros vinculados de manera estrecha con la práctica de la pintura.

\section{Conclusiones}

Un primer balance del inventario de la biblioteca de Cabrera revela que atendió a las recomendaciones de Palomino en la medida que fue selectivo en el acopio de libros de acuerdo con las demandas de sus clientes: el retrato y la pintura religiosa. Esto explica su interés en un gran retratista como Van Dyck, la gran cantidad de obras devotas y vidas de santos - sobre todo jesuitas, quienes fueron sus grandes clientes- y la bibliografía de tema guadalupano -asunto que le ocupó como pintor y como "teórico del arte". En síntesis, tanto la Maravilla americana como su obra pictórica, además del inventario de su biblioteca, son un indicio de que Miguel Cabrera fue un atento lector de El Museo pictórico y escala optica. Por un lado, esta evidencia obliga a considerar la obra de Palomino como un texto relevante tanto para las discusiones vinculadas con la fundación de una primera academia, como para problematizar diversos aspectos relativos a la práctica de la pintura hacia mediados del siglo XVIII en Nueva España. Por otro lado, revela que la coherencia de una biblioteca puede emerger desde el contenido de algunos de sus libros. De tal modo que el inventario, la obra escrita y la obra pictórica de Miguel Cabrera deben leerse de manera interrelacionada, es decir se explican de modo recíproco. Si bien el punto de partida es la reconstrucción de la biblioteca a través del análisis del inventario, es necesario conducir la interpretación hacia aspectos muchas veces elusivos, como el vínculo entre el modo de pintar y el modo de leer. En consecuencia, la posibilidad de que Miguel Cabrera fuera un pictor doctus, involucrado en los debates en torno al estatus liberal de la disciplina, no se infiere de la cantidad de libros que atesoró, sino de su obra pictórica y de su obra escrita, así como de sus lecturas, pero sobre todo surge de la suma de cada uno de los aspectos. La cuestión aquí no es dilucidar, si Miguel

72 El registro "374. Item, otro dicho: Llanto de la fama, en dos reales" puede ser identificado como Rodríguez del Toro, 1761. Memoria, descripción e inventario de los bienes que quedaron por fin y muerte de don Miguel de Cabrera. Ciudad de México, 26-V-1768 a 19-VIII-1768. Archivo Enrique A. Cervantes, sin signatura, f. 20. Tovar de Teresa, 1995: 284.

73 Becerra Moreno, 1766; Valcárcel Baquerizo, 1767; Tovar de Teresa, 1995: 254-255; Cuadriello, 1994: $284-287$. 
Cabrera fue cabalmente un pictor doctus -calificación que la historiografía asumió quizá de manera precipitada-, sino poner de relieve en qué medida sus libros contribuyen a matizar y redefinir esta etiqueta en el panorama de la pintura novohispana del siglo XVIII. Sobre todo, reflexionar acerca de que no es la cantidad de libros, ni su simple clasificación temática lo que convierte a un pintor en un "artista liberal", sino una serie de factores interrelacionados que es necesario sopesar como líneas de investigación derivadas de estas reflexiones. Un nuevo examen del inventario de los libros pertenecientes a Miguel Cabrera, más allá de los enfoques cuantitativos relacionados con la historiografía de mediados del siglo XX, también subraya la importancia de consolidar formas de trabajo entre diversos campos. A partir de esta perspectiva el vínculo entre la Historia del Arte y la Historia del Libro adquiere una nueva dimensión y una mutua interdependencia.

\section{Referencias bibliográficas}

Alcalá, Luisa Elena - Brown, Jonathan (eds.). Pintura en Hispanoamérica, 1550-1820. Madrid: El Viso, 2014.

Antídoto. Antídoto contra todo mal, la devocion a la Santisima Madre del Lumen. México: Joseph Bernardo de Hogal, 1737.

Armenini, Giovanni Battista. De veri precetti della pittura. Ravenna: Francesco Tebaldini, 1587.

- De los verdaderos preceptos de la pintura, editado por Bernárdez Sanchís, María Carmen. Madrid: Visor, 1999.

Báez Macías, Eduardo. Historia de la Escuela Nacional de Bellas Artes (Antigua Academia de San Carlos) 1781-1910. México: Universidad Nacional Autónoma de México, 2009.

Becerra Moreno, Juan. Relación del funeral entierro, y exequias de el Illmo. D. Manuel Rubio y Salinas, Arz. que fué de esta Santa Iglesia Metropolitana de México. México: Colegio de S. Ildefonso, 1766.

Becerra Tanco, Luis. Felicidad de México en el principio, y milagroso origen, que tuvo el Santuario de la Virgen María Nuestra Señora de Guadalupe. Sevilla: Thomas Lopez de Haro, 1685.

Bialostocki, Jan. The Message of Images: Studies in the History of Art. Viena: Irsa, 1988.

Brown, Jonathan. Imágenes e ideas en la pintura española del siglo XVII. Madrid: Alianza, 1980.

Burke, Marcus. Pintura y escultura en Nueva España: el barroco. México: Grupo Azabache, 1992.

Cabrera, Miguel. Maravilla americana y conjunto de raras maravillas. México: Real Colegio de San Ildefonso, 1756.

Cabrera y Quintero, Cayetano. Escudo de Armas de Mexico: México, Viuda de J. B. de Hogal, 1746.

Cacho Casal, Marta P. Francisco Pacheco y su Libro de retratos. Madrid: Marcial Pons, 2011.

Calvo Serraller, Francisco. Teoría de la pintura del siglo de oro. Madrid: Cátedra, 1999.

Caramuel Lobkowitz, Juan. Architectura civil recta y obliqua, 2 tomos. Vigevano: Camillo Corrado, 1678.

Carducho, Vicente. Dialogos de la pintura. Su defensa, origen, essencia, definicion, modos y diferencias. Madrid: Francisco Martinez, 1633. 
- Dialogos de la pintura. Su defensa, origen, essencia, definicion, modos y diferencias, editado por Francisco Calvo Serraller, Madrid: Turner, 1979.

Carrillo y Gariel, Abelardo. El pintor Miguel Cabrera. México: Instituto Nacional de Antropología e Historia, 1966.

Cuadriello, Jaime. "El obrador trinitario o María de Guadalupe creada en idea, imagen y materia”. En El divino pintor: la creación de María de Guadalupe en el taller celestial, editado por Cuadriello, Jaime - Mues Orts, Paula - Granados Salinas, Rosario Inés. México: Museo de la Basílica de Guadalupe, 2001, 61-205.

Cuadriello, Jaime (ed.): Juegos de Agudeza e ingenio. La pintura emblemática de la Nueva España, Catálogo de la exposición Museo Nacional de Arte (noviembre 1994 - febrero 1995). México: Consejo Nacional para la Cultura y las Artes, 1994.

Cuadriello, Jaime - Mues Orts, Paula - Granados Salinas, Rosario Inés. El divino pintor: la creación de María de Guadalupe en el taller celestial. México: Museo de la Basílica de Guadalupe, 2001.

Damm, Heiko - Thimann, Michael - Zittel, Claus (eds.). The Artist as Reader: On Education and Non-Education of Early Modern Artists. Leiden - Boston: Brill, 2013.

Docampo, Javier - Riello, José (ed.) La Biblioteca del Greco. Madrid: Museo Nacional del Prado, 2014.

Dyck, Antoon van. Icones principum, virorum doctorum, pictorum... Amberes: Hendricx, 1646.

Florencia, Francisco de. La estrella de el norte de Mexico aparecida al rayar el dia de la luz evangelica en este Nuevo-Mundo. México: Antonio Velazquez, 1741.

Gállego, Julián. Visión y símbolos en la pintura española del Siglo de Oro. Madrid: Aguilar, 1972.

García, Francisco. Vida, virtudes, y milagros de S. Ignacio de Loyola ... Madrid: Juan Garcia Infançon, 1685.

García Aguilar, Idalia. "Confieso que he leído o cuando menos poseído: memoria de libros particulares en la Nueva España", Inquire. Revista de Estudios Inquisitoriales, $\mathrm{n}^{\circ} 1$ (2013), 19-39.

Garriga, Joaquín. Renacimiento en Europa, Fuentes y documentos para la Historia del Arte vol. IV. Barcelona: Gustavo Gili, 1983.

Gutiérrez Haces, Juana. "Nacimiento de San Ignacio y profecías que le precedieron” y "Dios confirma la santidad de san Ignacio...". En Revelaciones. Las artes en América Latina, editado por Rishel, Joseph J. - Stratton-Pruitt, Suzanne. México: Fondo de Cultura Económica, Antiguo Colegio de San Ildefonso, 2007: 402-403.

Hellwig, Karin. La literatura artística española del siglo XVII. Madrid: El Viso, 1999.

— "El parangón en la España del siglo de oro: un debate entre la teoría y la práctica del arte”. En 'Sacar de la sombra lumbre'. La teoría de la pintura en el siglo de oro (15601724), editado por Riello, José. Madrid: Abada, Museo Nacional del Prado, 2012: 223 238.

Kagan, Richard - Marías, Fernando. "El pictor doctus en la Europa Moderna y El Greco como pintor filósofo". En La Biblioteca del Greco, editado por Docampo, Javier - Riello, José. Madrid: Museo Nacional del Prado, 2014, 15-39.

Kruft, Hanno-Walter. Historia de la teoría de la arquitectura, 2 vols. Madrid: Alianza, 1985.

La divozione. La divozione di Maria Madre Santissima del Lume distribuita in tre parti ... da un sacerdote della Compagnia di Gesù, 2 tomos. Palermo: Stefano Amato, 1733.

La devoción. La devocion de Maria Madre Santissima de la Luz distribuida en tres partes por un Sacerdote de la Compañia de Jesus, traducido por Lucas Rincon (SJ), 2 tomos. 
México: Imprenta Real del Superior Gobierno y del Nuevo Rezado de Doña María de Rivera, 1737-1738.

López Piñero, José María. El grabado en la ciencia hispánica. Madrid: Consejo Superior de Investigaciones Científicas, 1987.

María de Jesús de Ágreda (sor), Mística ciudad de Dios. Madrid: Bernardo de Villa-Diego, 1670.

- Mystica ciudad de Dios, 4 vols. Madrid: Imprenta de la Causa de la V. Madre, 1723.

- Mística ciudad de Dios, editado por Celestino Solaguren, México, Mínimos Franciscanos, 1985.

Marías, Fernando - Bustamante García, Agustín. Las ideas artísticas de El Greco. Comentarios a un texto inédito. Madrid: Cátedra, 1981.

Martínez, Martín. Anatomia completa del hombre. Madrid: Bernardo Peralta, 1728.

Mauquoy-Hendrickx, Marie. L'iconographie d'Antoine Van Dyck: catalogue raisonné, 2 vols. Bruselas: Bibliothèque Royale Albert I, 1991.

McGrath, Elizabeth. Rubens Subjects from History, Corpus Rubenianum vol. XIII-1. Londres: Harvey Miller Publishers, 1997.

Moran Turina, Miguel - Portús Pérez, Javier. El arte de mirar. La pintura y su público en la España de Velázquez. Madrid: Istmo, 1997.

Moyssén, Xavier. "La primera academia de pintura en México". Anales del Instituto de Investigaciones Estéticas, vol. IX, no 34 (1965), 15-29.

Mues Orts, Paula. La libertad del pincel. Los discursos sobre la nobleza de la pintura en la Nueva España. México: Universidad Iberoamericana, 2008.

— "El pintor novohispano José de Ibarra: imágenes retóricas y discursos pintados". Tesis doctoral, Universidad Nacional Autónoma de México, 2009.

Pacheco, Francisco. Arte de la pintura. Sevilla: Simon Faxardo, 1649.

- El arte de la pintura, editado por Basegoda i Hugas, Bonaventura. Madrid: Cátedra, 2001.

Palomino, Antonio. El Museo pictórico y escala optica, tomos I y II. Madrid: Lucas Antonio de Bedmar, 1715.

- El Parnaso español, pintoresco y laureado, tomo III. Madrid: Viuda de Juan García Infanzon, 1724.

Portús Pérez, Javier. Pintura y pensamiento en la España de Lope de Vega. Madrid: Nerea, 1999.

Portús Pérez, Javier (ed.). Fábulas de Velázquez. Mitología e Historia Sagrada en el Siglo de Oro. Madrid: Museo Nacional del Prado, 2008.

Pozzo, Andrea del. Perspectiva pictorum et architectorum, 2 vols. Roma: Joannis Jacobi Komarek, 1693-1700.

Ratto, Cristina. "Los libros del arquitecto. Cultura letrada y arquitectura en el siglo XVII novohispano". En Conocimiento y Cultura. Estudios Modernos en la Facultad de Filosofía y Letras, editado por Adriana Álvarez Sánchez. México: Universidad Nacional Autónoma de México, 2016, 181-221.

Riello, José. "La biblioteca del Greco". En La Biblioteca del Greco, editado por Docampo, Javier - Riello, José. Madrid: Museo Nacional del Prado, 2014, 41-77.

Riello, José (ed.). 'Sacar de la sombra lumbre'. La teoría de la pintura en el siglo de oro (1560-1724). Madrid: Abada, Museo Nacional del Prado, 2012.

Rishel, Joseph - Stratton-Pruitt, Suzanne (eds.). Revelaciones. Las artes en América Latina. México: Fondo de Cultura Económica, Antiguo Colegio de San Ildefonso, 2007.

Rodríguez del Toro, José. Llanto de la fama reales exequias de la serenissima señora Da. María Amalia de Saxonia, reyna de las España, celebradas en la santa iglesia cathedral 
de la imperial corte mexicana, los dias 17 y 18 de julio de 1761. México: Cristóbal y Felipe de Zuñiga y Ontiveros, 1761.

Rodríguez Moya, Inmaculada. El retrato en México, 1781-1867. Héroes, ciudadanos y emperadores para una nueva nación. Sevilla: Universidad de Sevilla, 2006.

Ruiz de Arcaute, Agustín. Juan de Herrera, arquitecto de Felipe II. Madrid: Espasa-Calpe, 1936.

Ruiz Pérez, Pedro. De la pintura y las letras: la biblioteca de Velazquez. Sevilla: Junta de Andalucía, Consejería de Cultura, 1999.

Sánchez Cantón, Francisco Javier. "La librería de Velázquez". En Homenaje a don Ramón Menéndez Pidal, vol. III, Madrid: Centro de Estudios Históricos, 1925, 379-406.

— "Como vivía Velázquez. Inventario descubierto por D. F. Rodríguez Marín”, en Archivo Español de Arte, vol. 15, nº 50 (1942), 66-91.

— “Los libros españoles que poseyó Velázquez". En Varia Velazqueña. Homenaje a Velázquez en el III centenario de su muerte, vol. I. Madrid: Consejo Superior de Investigaciones Científicas, 1960, 640-648.

Scheuchzer, Johann Jakob. Physica sacra, 4 vols. Augsburg - Ulm: Christian Ulrich Wagner, $1731,1732,1733$ y 1735 .

Schlosser, Julius. La literatura artística. Madrid: Cátedra, 1993.

Soto, Myrna. El arte maestra. Un tratado de pintura novohispano. México: Universidad Nacional Autónoma de México, 2005.

Spicer, Joaneath A. "Anthony Van Dyck's Iconographie: an Overview or its Preparation". Studies in the History of Art, vol. 46 (1994), 325-364.

Torres Santo Domingo, Marta. "La estela de la Biblia Políglota: la colección bíblica de la Biblioteca Complutense". En V Centenario de la Biblia Políglota Complutense, dirigido por Gonzalo Sánchez-Molero, José Luis. Madrid: Universidad Complutense, 2014, 163-188.

Toussaint, Manuel. Pintura colonial en México. México: Imprenta Universitaria, 1965.

Tovar de Teresa, Guillermo. Bibliografía novohispana de arte, 2 vols. México: Fondo de Cultura Económica, 1988.

- Miguel Cabrera: pintor de cámara de la reina celestial. México: InverMéxico Grupo Financiero, 1995.

Valcárcel Baquerizo, Domingo. Reales exequias de la serenissima señora Da. Isabel Farnecio princesa de Parma y reyna de las Españas, celebradas en la Santa Iglesia Cathedral en la imperial Corte Mexicana, los dias 27 y 28 de febrero de 1767. Mexico: Phelipe de Zuñiga y Ontiveros, 1767.

Valverde de Amusco, Juan. Historia de la composicion del cuerpo humano. Roma: Antonio Salamanca y Antonio Lafreri, 1556.

Varchi, Benedetto. Due lezzioni di M. Benedetto Varchi, nella prima delle quali si dichiara un sonetto di M. Michelagnolo Buonarroti. Nella seconda si disputa quale sia più nobile arte, la scultura, o la pittura, con una lettera d'esso Michelagnolo e più altri eccelentissimi pittori et scultori, sopra la questione sopradetta. Florencia: Lorenzo Torrentino, 1549.

- Leccion que hizo Benedicto Varqui en la Academia Florentina (...) sobre la primacia de las artes, y qual sea mas noble, la escultura ó la pintura con una carta de Michael Angelo Buonarroti y otras de los mas célebres pintores y escultores, trad. Felipe de Castro. Madrid: Eugenio Bieco, 1753.

Vesalio, Andrés. De humani corporis fabrica libri septem. Basilea: Joannes Oporinus, 1543. Zaragoza Reyes, Verónica Aurelia. "Vida de San Ignacio de Loyola (1757), serie pictórica de la Casa Profesa de México. Estudio y catálogo". Tesis de Maestría, Universidad Iberoamericana Ciudad de México, 2012. 